DOI 10.37882/2223-2982.2020.12-2.09

\title{
ПЕРЕВОД ИНОЯЗЫЧНЫХ ВКРАПЛЕНИЙ В ТЕКСТЕ АНГЛОЯЗЫЧНОГО РОМАНА Д. ТАРРТ «ЩЕГОЛ» НА РУССКИЙ ЯЗЫК
}

\section{TRANSLATION OF FOREIGN INCLUSIONS IN D. TARRT'S ENGLISH NOVEL THE GOLDFINCH INTO RUSSIAN}

N. Gatsura

A. Tirbakh

Summary: The purpose of this research is to establish ways of transferring foreign language inclusions of the English-language original in the translation of the novel into Russian. The study used the method of contextual analysis, comparative and descriptive methods. Russianlanguage inclusions (35 units) in the text of the novel in English were transliterated in Latin; for their transmission in the translation of the novel into Russian, a zero translation was used while preserving the spelling of inclusions in the Latin alphabet. Foreign language inclusions of other languages (87 units) in most cases, when translated into Russian, were transmitted using a zero translation with a commentary of the translator in a separate footnote (79 inclusions, $90.8 \%$ ), there was also a zero translation without comment ( 6 inclusions, $6,9 \%$ ), transliteration (1 blotch, 1.1\%) and omission (1 blotch, 1.1\%). The method of transferring foreign language inclusions in translation primarily depends on the language of the inclusions. If the language of the inclusions coincides with the translating language, the inclusions should be transmitted using a zero translation while preserving the spelling in the Latin alphabet in order to distinguish between the two languages and indicate the heterogeneity of speech. Inclusions in languages other than the translating language should be kept in the same form in the translation text, but their translation should be given in a note with a reference to the source language (zero translation with a translation commentary). The omission of inclusions leads to a change in the structure of the original text, and also does not convey the speech features of the characters in full.

Keywords: foreign language blotting, translation method, zero translation, translation commentary, translation transformation.
Гацура Наталья Игоревна

к.филол.н., доцент, Омский государственный университет

n.gatsura@7gmail.com

Тирбах Анастасия Олеговна

Университет имени Ло́ранда Э́твёша, Будапешт anastasiya_tirbakh@mail.ru

Аннотация: Цель данного исследования, установить способы передачи иноязычных вкраплений англоязычного оригинала в переводе романа на русский язык. В исследовании применены метод контекстуального анализа, сопоставительный и описательный методы. Русскоязычные вкрапления (35 единиц) в тексте романа на английском языке были транслитерированы латиницей; для их передачи в переводе романа на русский был использован нулевой перевод с сохранением написания вкраплений на латинице. Иноязычные вкрапления других языков (87 единиц) в большинстве случаев при переводе на русский язык были переданы при помощи нулевого перевода с комментарием переводчика в отдельной сноске (79 вкрапление, 90,8\%), также отмечался нулевой перевод без комментария (6 вкраплений, 6,9\%), транслитерация (1 вкрапление, 1,1\%) и опущение (1 вкрапление, 1,1\%). Способ передачи иноязычных вкраплений в переводе прежде всего зависит от языка вкрапления. Если язык вкрапления совпадает с переводящим языком, следует передавать вкрапление при помощи нулевого перевода с сохранением написания на латинице с целью разграничения двух языков и указания на неоднородность речи. Вкрапления на языках, отличных от переводящего языка, следует сохранять в том же виде в тексте перевода, но давать их перевод в примечании со ссылкой на язык-источник (нулевой перевод с переводческим комментарием). Опущение вкраплений ведет к изменению структуры текста оригинала, а также не передает речевые особенности персонажей в полной мере.

Ключевые слова: иноязычное вкрапление, способ перевода, нулевой перевод, переводческий комментарий, переводческая трансформация.

глобализации интересом к произведениям литературы, востребованностью художественного перевода, а также необходимостью передачи в художественном переводе не только смысла исходного сообщения, но и авторского стиля, интенции, эстетического и прагматического эффекта оригинала. Все это делает художественный перевод одним из самых трудоемких видов перевода. Сложность передачи речи персонажей, содержащей иноязычные вкрапления (речевые единицы с иносистемными признаками в окружении единиц данного языка), 
заключается в отсутствии непосредственных эквивалентов употребляемых персонажами единиц на языке перевода, а также наличии определенных межкультурных и прочих различий. Иноязычные вкрапления создают речевой портрет персонажа, передают местный колорит и атмосферу, повышают экспрессивность высказывания.

Что касается способов перевода таких вкраплений, то на настоящий момент не выделено единого образца, предписывающего план оформления иноязычных вкраплений в тексте, соответственно эта проблема требует индивидуального подхода. Более того, проблема усугубляется в случае, если вкрапления, иноязычные для текста оригинала, написаны на языке перевода.

Объектом исследования являются иноязычные вкрапления в англоязычном романе Д. Тартт «Щегол».

Предметом исследования являются способы перевода иноязычных вкраплений в художественном пространстве романа с английского языка на русский.

Цель данной работы: выявление способов перевода иноязычных вкраплений в англоязычном художественном тексте на русский язык.

Новизна проведенного исследования заключается в использовании актуального материала - романа получившей признание современной американской писательницы.

Практическая значимость заключается в том, что в данной работе были выделены определенные переводческие стратегии при переводе иноязычных вкраплений, которые в дальнейшем могут быть применены при переводе других художественных произведений. Полученные выводы могут быть использованы на занятиях теории и практике перевода, по переводу художественного текста, стилистике английского языка.

\section{Материалы и методы}

Материалом исследования послужили 85 текстовых извлечений, содержащих 122 иноязычных вкрапления, из художественного англоязычного произведения Д. Тартт «Щегол» и 85 текстовых извлечений из русскоязычного перевода романа Анастасии Завозовой.

В исследовании были использованы следующие методы: описательный метод, метод сопоставительного и контекстуального анализа. В качестве метода статистической обработки материала использовался метод количественного анализа.

\section{ヘитературный обзор}

Обратимся к определению иноязычных вкраплений и их роли в художественном тексте.

Существует несколько определений иноязычных вкраплений, первое из них было предложено Л.П. Крысиным. Исследователь делает акцент на самом говорящем, употребление им иностранных слов «обусловлено степенью знакомства говорящего с иностранным языком, стилистическими или жанровыми особенностями речи» [9, с. 47]. В.С. Гимпелевич отмечает степень ассимилированности иноязычных вкраплений, рассматривая их как полностью или частично иносистемные графические, морфемные или семантические признаки в окружении единиц данного языка [4, с. 89]. Н.Л. Еремия подразумевает под иноязычными вкраплениями безэквивалентную лексику, экзотизмы. [6, с. 84]. Иноязычные вкрапления в художественном тексте рассматриваются как стилистический аспект авторского идиостиля [8, с. 18].

В данном исследовании определим иноязычные вкрапления как отличные по своему графическому, фонетическому, грамматическому оформлению от языка оригинала слова, словосочетания и предложения/высказывания.

Среди иноязычных вкраплений выделяют употребление в разных функциональных стилях любого языка слов и словосочетаний интернационального характера; а также иноязычные элементы как индивидуальное словоупотребление, служащие художественно-стилистическим задачам [9, с. 47-49]. Иноязычные вкрапления в текстах используются как атрибуты определенной речевой ситуации, указывая на место языкового контакта; цель общения; социальный статус и национальность говорящих и степень их владения родным и иностранным языком, психическое и физическое состояние говорящих [10, с. 24-26]. Также они создают речевой портрет персонажа [1, с. 157], придают тексту аутентичность, иногда и иронический эффект [3, с. 263-265]. Прагматическими функциями иноязычных вкраплений в художественном тексте являются: создание местного колорита (языковые элементы выступают в роли социокультурных маркеров); экзотикация (передача нестандартного характера описываемых лиц и действий, придание повествованию загадочности; эвфонизация (способствует благозвучию высказывания); фасцинация (привлечение внимания читателей) [11, с. 97-98]. Отмечается приобретение иноязычными вкраплениями особого стилистического потенциала, экспрессивности при включении в художественную систему произведения [13, с. 121-122].

В текст произведения иноязычные вкрапления вводятся в неизмененном виде без дополнительных пояснений (их смысл может быть понятен из контекста; они относятся к элементам колорита, что делает важной форму вкрапления, а не ее смысл); с дальнейшим объясне- 
нием автором значения использованного иноязычного вкрапления (комментарий) [3, с. 263-265]; через перевод вкрапления в самом тексте; транскрибирование [2, с. 80].

В последнее время проблема функционирования иноязычных вкраплений (далее ИВ) в текстах разных жанров и разных авторов, а также стратегии перевода иноязычных вкраплений с сохранением стилистического и прагматического эффекта нашла отражение в работах следующих исследователей: Т.А. Алексейцева, М.А. Дубовицкая, Л.П. Жулева, Р.А. Валеева и И.Н. Мартынова, С.И. Манина, Т.М. Метласова, В.Ю. Немонежная и др. Все эти исследователи поднимают проблему сохранения как смысла исходного текста, имеющего иноязычные вкрапления, так и передачу языковых форм, уникального авторского стиля. М.А. Дубовицкая делает упор на психологическом аспекте использования иноязычных вкраплений, на проблеме самоидентификации и саморепрезентации автора; на подтексте, который создают ИВ в произведении, отражая мировоззрение и духовный опыт писателя, его культурную идентичность [5, с.89-96]. Л.П. Жулева указывает на ИВ, функционирующие как элементы авторского стиля, жанровых поисков автора. Исследователь говорит о необходимости разработки стратегий комплексного переноса ИВ оригинала в текст перевода, приходя к выводу, что контекстуальные замены не являются эффективным способом перевода [7, с. 179-193]. Р.А. Валеева и И.Н. Мартынова обращают внимание на зависимость способа перевода от фоновых знаний реципиентов оригинала и перевода и собственно степени универсальности ИВ: если восприятие смысла ИВ не вызовет затруднения у реципиентов перевода, то его нужно оставить в оригинальном виде, в других случаях требуется переводческий комментарий. Поиск эквивалента ИВ в переводящей культуре не всегда является удачным решением, поскольку ведет к утрате национального компонента [17, р. 1863-1875]. Е.Н. Моисеева на неудачность переноса формы ИВ в текст перевода даже с его графическим выделением курсивом или астериском, использованием подстрочного комментария. Исследователь рекомендует на своем материале для анализа использовать компенсацию [14, с. 147-48]. Т.М. Метласова, исследуя творчество Т. Пратчетта, использующего ИВ для создания макаронической речи (бесполезного смешения разноязычных слов), приходит к выводу о целесообразности применения в переводе культурной адаптации (преобразование чужеродных элементов оригинала в элементы, характерные для принимающей культуры и позволяющие сохранить тот же самый прагматический эффект) [11, 2015]. В.Ю. Немонежная считает, что выбор того или иного способа перевода иноязычных вкраплений зависит от временных параметров (целесообразность пояснения вышедшим из обихода словам); от цели, которую ставит себе переводчик (воссоздание атмосферы оригинала или максимальное облегчение восприятия чужеродных элементов для реципиента по- средством их перевода этих), переводческой традиции $[15,2006]$.

\section{Обсужкение}

Обратимся к роману Д. Таррт «Щегол» и его переводу. В центре сюжета романа Донны Тартт «Щегол» (2013) - тринадцатилетний Тео Декер, вынесший в состоянии шока при взрыве в музее редкую картину Карела Фабрициуса. Мать Тео погибает, и у Тео развивается одержимость картиной «Щегол»: о ней говорила его мать перед смертью. Действие романа происходит в 2008-2017 годах в Нью-Йорке, Лас-Вегасе и в Амстердаме. Действующие лица относятся к разным национальным, социальным и возрастным группам, что ярко отображается в речи персонажей.

Перейдем непосредственно к анализу иноязычных вкраплений в англоязычном тексте романа. В романе «Щегол» было обнаружено 85 текстовых фрагментов, в которых были использованы иноязычные вкрапления (122 единицы). В результате анализа вкрапления были разделены по языковому признаку на следующие группы:

а) нидерландские (41 единица) - используются для отображения местного колорита, были введены в произведение, когда действие происходило в Нидерландах;

b) французские (12 единиц) - употребляются персонажами, относящимися к творческой элите, с целью создания более возвышенного стиля;

с) испанские (18 единиц) - 12 из них выполняют функцию отображения этнической принадлежности испанцев, проживающих в США $(66,6 \%$ случаев, и 6 (33,3\%) использованы персонажамиамериканцами в разговоре с испанцами, а также как приобретенная речевая особенность (после долгого общения с испанцами) при общении с персонажами-американцами и во внутренних монологах;

d) немецкие (11 единиц) - указывают на этническую принадлежность немцев, проживающих в Нидерландах;

е) русские (35 единицы) - 23 вкрапления (65,7\%) использованы в речи русских персонажей, соответственно, указывают на этническую принадлежность, и 12 вкраплений (34,3\%) употреблены в речи американцев, тесно общающихся с русскоязычными персонажами;

f) польские (5 единиц) - показывают этническую принадлежность

Таким образом, основными функциями иноязычных вкраплений в романе «Щегол» являются указание на этническую принадлежность, передача местного колорита, создание элемента возвышенности речи и процесс заимствования иностранной лексики персонажами- 
американцами.

Для удобства исследования мы разделили вкрапления на две группы: русскоязычные вкрапления и вкрапления на других иностранных языках, поскольку подход к переводу русскоязычных вкраплений отличается от прочих.

Русскоязычные вкрапления (35 единиц) в тексте романа на английском языке были транслитерированы латиницей; для передачи данных вкраплений в переводе романа на русский был использован нулевой перевод, при котором было сохранено написание вкраплений на латинице. Данное переводческое решение объясняется тем, что необходимо разграничить основной текст перевода романа на русском от использованных вкраплений, так как и вкрапления, и перевод являются русскоязычными. Рассмотрим пример русскоязычных вкраплений в оригинальном тексте романа: Boris introduced us in Russian. "Privet! Myenya zovut Anatoly," said the guy... [18]. Речь на русском языке была выделена курсивом для маркирования вкрапления в англоязычном тексте и написана на латинице с целью того, чтобы англоязычные читатели смогли узнать примерное звучание произнесенной фразы. В переводе на русский язык написание и оформление этой фразы полностью сохраняется, то есть был использован нулевой перевод: «Борис представил нас по-русски. - Privet! Myenya zovut Anatoly, - сказал мужик, ...» [16]. Благодаря такому оформлению, читатель замечает неоднородность речи и понимает, что, в отличие от других элементов текста, именно эта часть была изначально произнесена на русском. Считаем такую передачу русскоязычных вкраплений оптимальной, поскольку она четко разграничивает две языковые группы, а также не требует дополнительных вставок, как если бы фраза была написана на кириллице, а затем было добавлено примечание с указанием на язык - «...сказал он на русском». Однако, некоторые вкрапления были изменены при переводе, что отображено в табл. 1:

В этих случаях в процессе перевода была изменена форма слова с целью соблюдения грамматических правил в языке перевода, либо для согласования с предыдущей частью предложения, также для соблюдения норм сочетаемости в русском языке была заменена лексема. Считаем, такие переводческие решения применительно к данному материалу обоснованными. В четырех текстовых фрагментах в оригинале был дан перевод русской фразы на английский, например: "Govorite medlenno, I said, speak slowly, and Povtorite, pozhaluysta. Repeat, please" [18]. В таком случае перевод на русский был бы излишним, ведь смысл фразы и так понятен русским читателям; поэтому в русском переводе романа вкрапления, как и в других случаях, передаются при помощи нулевого перевода с сохранением написания на латинице: «Govorite medlenno, говорил я. Povtorite, pozhaluysta» [16].

Таким образом, можно отметить, что при передаче русскоязычных вкраплений в переводе на русский язык следует прибегать к нулевому переводу с сохранением написания вкраплений на латинице для отображения неоднородности речи. Однако, в процессе перевода можно несколько изменять форму слова или же заменять само слово на другое с той же стилистической окраской для соблюдения лексических и грамматических норм русского языка. В случае, если в тексте оригинала русскоязычному вкраплению дается перевод, во избежание смысловой избыточности его следует опускать, поскольку русскому читателю он не требуется; сами же вкрапления, как и в других случаях, следует транслитерировать для разграничения двух языков.

Трансформации при переводе русскоязычных вкраплений

Таблица 1

\begin{tabular}{|c|c|c|}
\hline Оригинал & Перевод & Комментарий \\
\hline $\begin{array}{l}\text { Though his Australo-Ukrainian accent was certainly } \\
\text { very odd, he was almost as fluent in English as } \\
\text { I was; and considering what a short time he'd } \\
\text { lived in America he was reasonably conversant in } \\
\text { amerikanskii ways [18]. }\end{array}$ & $\begin{array}{l}\text { Его австрало-украинский акцент звучал, конеч- } \\
\text { но, странно, но на английском он говорил прак- } \\
\text { тически не хуже меня, и если учесть то, как не } \\
\text { долго он жил в Америке, во многом он вел себя } \\
\text { уже как настоящий amerikkanets [16]. }\end{array}$ & $\begin{array}{l}\text { В данном случае произошла грамматическая } \\
\text { трансформация, так как прилагательное было } \\
\text { заменено на однокоренное существительное для } \\
\text { согласования с остальной частью предложения. }\end{array}$ \\
\hline $\begin{array}{l}\text { "Is snowing there?" Shaking my shoulder. "Man says } \\
\text { is snowing, crazy man, ty videsh?! Snowing in Dubai! } \\
\text { A miracle, Potter! Look!" [18]. }\end{array}$ & $\begin{array}{l}\text { — Там снег, да? — он потряс меня за плечо. —- } \\
\text { Мужик говорит, там снег, дурила, ty vidish? Снег в } \\
\text { Дубае! Чудеса, Поттер! Смотри! [16]. }\end{array}$ & $\begin{array}{l}\text { В слове videsh было изменено окончание в соот- } \\
\text { ветствии с правилами русского языка. }\end{array}$ \\
\hline $\begin{array}{l}\text { "You got fat! He got fat!" he said indignantly as } \\
\text { Popchik jumped up and kissed him on the face."You } \\
\text { let him get fat! Yes, hello, poustyshka, little bit of } \\
\text { fluff you, hello! You remember me, don't you?" [18]. }\end{array}$ & $\begin{array}{l}\text { Ты растолстел! Он растолстел! — с возмущени- } \\
\text { ем сообщил Борис, когда Попчик рванувшись } \\
\text { вперед, облизал ему лицо. — Ты его раскормил! } \\
\text { Да-да, привет, gloupysh, ты маленький пушистик, } \\
\text { привет! Помнишь меня, да? [16]. }\end{array}$ & $\begin{array}{l}\text { Здесь слово poustyshka было заменено на } \\
\text { gloupysh в результате лексико-семантические за- } \\
\text { мены модуляции, поскольку русскому читателю } \\
\text { может показаться странным такое обращение к } \\
\text { собаке, как «пустышка». }\end{array}$ \\
\hline
\end{tabular}


Иноязычные вкрапления других языковых групп (87 единиц) в большинстве случаев при переводе на русский язык были переданы при помощи нулевого перевода с комментарием переводчика в отдельной сноске (79, $90,8 \%)$, также отмечался нулевой перевод без комментария $(6,6,9 \%)$, транслитерация $(1,1,1 \%)$ и опущение (1, $1,1 \%)$. Рассмотрим выделенные переводческие решения на примерах.

\section{1. Нулевой перевод с переводческим комментарием}

"I been thinking about you and your mother so much," he said, wiping his brow. "Ay bendito. I can't-I don't even know what you must be going through." [18]. В данном текстовом фрагменте иноязычное вкрапление выделено курсивом с целью указания на неоднородность речи; автором не указывается, на каком именно языке оно было произнесено в данном случае, но читатель понимает это из контекста, так как говорящий - испанец. В переводе было сохранено написание вкрапления на латинице, а также добавлено примечание с переводом и ссылкой на язык вкрапления: - Я все думал о тебе и о твоей маме, - сказал он, утирая лоб. - Ay bendito [31]. Не могу... не знаю даже, каково тебе приходится [16]. 31. Господи благослови (ucn.). [16].

Такой способ передачи иноязычных вкраплений является самым распространенным в переводе романа «Щегол» на русский язык (81 вкрапление, 91\%). Все примечания находятся в конце книги, соответственно они не нагружают основной текст романа, а также сохраняют его оригинальную форму, ведь на английском языке не дается перевод вкраплений. Нулевой перевод с переводческим комментарием сохраняет элемент инородности речи в тексте, но вместе с тем дает читателю необходимые сведения для понимания всего высказывания.

\section{2. Нулевой перевод без переводческого комментария}

Например, Que faire? as my mother had liked to say [18]. В тексте оригинала вкрапление выделено курсивом, что выделяет его на фоне англоязычного текста романа. В переводе оформление высказывания сохранено, но отсутствует примечание с переводом, а также ссылка на язык: «Que faire? как любила говорить мама» [16]. Данный способ перевода не является адекватным, так как читатель упускает информацию, передающуюся в этом вкраплении: 1) само значение фразы «Что поделать?», 2) употребление французского языка (предположительно, весьма частое) матерью Тео, что является штрихом к созданию ее речевого портрета. В данном случае следует также использовать переводческий комментарий в примечаниях. Тем не менее, нулевой перевод без переводческого комментария может быть применен в том случае, если значение вкрапления понятно из контекста.

\section{3. Опущение}

Рассмотрим следующий пример: Boris-leaning back on his hands, face turned to the sky - was singing to himself in Polish. Wszystkie dzieci, nawet źle/, pogrążone sq we śnie,/ a Ty jedna tylko nie./ A-a-a, a-a-a... [18]. В оригинале указывается язык и характер вкрапления, которое выделяется курсивом. В русском переводе вкрапление полностью опущено: «Борис, опершись на отставленные назад руки, запрокинув голову, пел себе под нос по-польски.» [16]. В переводе так же указан характер и язык, но само вкрапление отсутствует, из-за чего нарушается форма текста и речевая характеристика персонажа не передается в полной мере. В последующей же части, когда Борис продолжил петь ту же песню, переводчик сохраняет форму вкрапления, но не выделяет его курсивом и использует нулевой перевод: «Борис что было сил горланил все ту же песенку: A-a-a, a-a-a,/ byly sobie kotki dwa./ A-a-a, kotki dwa, / szarobure...» [16].

Нулевой перевод данного вкрапления и опущение вкрапления во фрагменте выше объясняется тем, что далее в тексте Борис сам переводит эту же песню на английский язык - основной язык романа, благодаря чему можно перевести только перевод Бориса на русский, не нарушая форму текста оригинала: «...он запрокинул голову и запел: Спи, мой милый, / С неба дам тебе звезду, / Все-все детки спят, / И плохие детки спят, / Все спят дети, / Только ты не спишь, / А-а-а-а... / Жили-были два котенка...» [16].

Таким образом, во избежание избыточности можно опустить перевод вкрапления в примечании, если далее в самом тексте дается перевод; однако, не следует опускать вкрапление в тексте перевода, так как в таком случае нарушается форма текста оригинала и не передаются речевые особенности персонажа.

\section{4. Транслитерация}

Рассмотрим примеры с данным способом перевода: "Danke darling," said Horst. [18]. В данном примере вкрапление в тексте оригинала выделено курсивом, что разграничивает немецкое слово danke от английского darling. При передаче вкрапления на русский язык переводчик выбрала транслитерацию, применив ее ко всему высказыванию: - Данке, дарлинг, - сказал Хорст [16]. В результате переводчиком была нарушена общая стратегия передачи иноязычных вкраплений не на русском языке (нулевой перевод с переводческим комментарием), произошло смешение немецкого и английского, соответственно, была нивелирована инородность речи. Однословные вкрапления можно передавать транслитерацией для облегчения чтения, если их смысл понятен из контекста, а также, если это не нарушает общую переводческую стратегию; тем не менее, при таком способе передачи иноязычных вкраплений невозможно отде- 
лить их от основного текста.

Итак, иноязычные вкрапления в романе Д. Тартт «Щегол» помогают передать этническую принадлежность персонажей, отразить местный колорит, придать возвышенность речи, а также указать на речевые особенности персонажей-американцев, часто общающихся с иностранцами.

\section{Результаты}

Русскоязычные вкрапления (35 единиц) в тексте романа на английском языке были транслитерированы латиницей; для передачи данных вкраплений в переводе романа на русский был использован нулевой перевод, при котором было сохранено написание вкраплений на латинице. Иноязычные вкрапления других языковых групп (87 единиц) в большинстве случаев при переводе на русский язык были переданы при помощи нулевого перевода с комментарием переводчика в отдельной сноске (79 вкрапление было переведено этим способом, $90,8 \%)$, также отмечался нулевой перевод без комментария (6 вкраплений, 6,9\%), транслитерация (1 вкрапление, $1,1 \%)$ и опущение (1 вкрапление, 1,1\%).

Выбранные переводчиком способы перевода зависят от функции иноязычных вкраплений, языка самого вкрапления и языка перевода. Все русскоязычные вкрапления в переводе романа на русский язык переданы при помощи нулевого перевода, то есть были транслитерированы на латинице (как и в оригинале), благодаря чему создается эффект неоднородности речи. В процессе перевода допустимо несколько изменять граммати- ческую или фонетическую форму слова или же заменять само слово на другое с той же стилистической окраской, соблюдая лексические и стилистические нормы русского языка. Если персонаж переводит собственное высказывание на английский язык в оригинале произведения, этот фрагмент следует опускать и передавать только вкрапление, так как его значение будет понятно русскоязычному читателю и без перевода.

Самым удачным способом перевода иноязычных вкраплений на языках, отличных от переводящего языка, является нулевой перевод с переводческим комментарием в приложении; так сохраняется структура текста оригинала и эффект неоднородности речи. В случаях, когда значение вкрапления понятно из контекста, может быть применен нулевой перевод без переводческого комментария. При опущении вкрапления нарушается структура текста оригинала, а также не передаются определенные речевые характеристики персонажей, что считается серьезными смысловыми потерями.

\section{Зак^ючение}

Полученные выводы и рекомендации относительно способов перевода иноязычных вкраплений, играющих важную роль в восприятии художественного текста, могут быть использованы как практическое руководство при работе с иноязычными вкраплениями как в художественном, так и других видах перевода. Дальнейшие перспективы исследования видятся в исследовании перевода иноязычных вкраплений, функционирующих в произведениях других жанров, других авторов, на материале других языков.

\section{ЛИТЕРАТУРА}

1. Агеева А.В. Типология иноязычных вкраплений в русских текстах // Вестник Московского университета. - Серия 22: Теория перевода. - 2014. - №1. - C. 153-163.

2. Алексейцева Т.А. Иноязычные вкрапления в переводе // Проблемы Науки. - 2017. - №1. - [Электронный ресурс] URL: https://cyberleninka.ru/article/n/ inoyazychnye-vkrapleniya-v-perevode (Дата обращения - 29.11.2020).

3. Влахов С., Флорин С. Непереводимое в переводе: учебное пособие [Текст] / С. Влахов, С. Флорин. - М.: Международные отношения, 1980. - 342 с.

4. Гимпелевич В.С. Род имен существительных - иноязычных вкраплений в русском языке // Учен. зап. Минвуза Азерб. ССР. - 1974. - Ч. 12. - Сер. 4. C. $87-91$.

5. Дубовицкая М.А. Иноязычные вкрапления в художественном тексте как способ самоидентификации и авторепрезентации (на примере романа амина Ар-Рейхани «Книга Халида») // Филологические науки в МГИМО. М.: Московский государственный институт международных отношений (университет) Министерства иностранных дел Российской Федерации. № 1 (17), 2019. - С. 89-96.

6. Еремия Н.Л. 0 принципах отбора экзотизмов и иноязычных вкраплений в учебные толковые словари // Лингвистические исследования. - М. - 1976. №. 1. - - $.81-86$.

7. Жулева Л.П. Иноязычные вкрапления в прозе Э. А. По и их русская переводческая рецепция // Вестник Томского государственного университета. Филология. 2018. С. 179 - 193. [Электронный ресурc] URL: https://www.elibrary.ru/item.asp?id=36239369 (Дата обращения - 29.11.2020).

8. Краснова Т.В. Иноязычные вкрапления в русской литературной речи начала XX века [Текст]: автореф. дис.... канд. филол. наук / Т.В. Краснова. - Воронеж, 2009. - 26 c. - Режим доступа: https://dlib.rsl.ru/01003487669 (Дата обращения - 29.11.2020).

9. Крысин Л.П. Иноязычные слова в современном русском языке. М.: Наука, 1968. - 208 с.

10. Листрова-Правда Ю.Т. Отбор и употребление иноязычных вкраплений в русской литературной речи XIX века. - Воронеж: Изд. Воронежского ун-та, $1986 .-143$ с. 
11. Манина С.И. Прагматические функции иноязычных вкраплений [Текст] / С.И. Манина. // Вестник Адыгейского государственного университета. - Серия 2: Филология и искусствоведение. - 2010. - №1. - [Электронный ресурс]. URL: https://cyberleninka.ru/article/n/pragmaticheskie-funktsii-inoyazychnyh vkrapleniy (Дата обращения - 29.11.2020).

12. Метласова Т.М. Функционирование иноязычных вкраплений в художественном тексте и особенности их перевода на русский язык (на примере романа Т. Пратчетта «Ведьмы за границей») [Электронный ресурс]. URL: http://www.sgu.ru/sites/default/files/textdocsfiles/2015/02/26/metlasova_t.m_ shimarova_o.v.funkcionirovanie_inoyazychnyh_.pdf (Дата обращения - 29.11.2020).

13. Лупачева Т.А. Функционирование китайских вкраплений в произведениях американской писательницы Эми Тэн: дис.... канд.филол.наук. - Владивосток, 2005. - 139 с. - [Электронный ресурc]. URL: https://dlib.rsl.ru/01002942908 (Дата обращения - 29.11.2020).

14. Моисеева Е.Н. Способы передачи иноязычных вкраплений в переводах произведений М.А. Булгакова на английский и французский языки // Альманах современной науки и образования. Тамбов: Грамота, 2008. № 2. Ч. 1. С. 147-148.

15. Немонежная В.Ю. Иноязычные вкрапления в художественном тексте как переводческая проблема/ дис. на соискание ученой степени кандидата филологических наук М., 2006. 155 с.

16. Тартт Д. Щегол [Текст] / пер. с англ. А. Завозовой. - М.: АCT; Corpus, 2015. - 832 c.

17. Valeeva Roza A.; Martynova Irina N. Rendering of Foreign Language Inclusions in the Russian Translations of the Novels by Graham Greene // International Journal of Environmental and Science Education, Volume 11, \# 8 p.1863-1875. 2016. [Электронный ресурc] URL: https://www.researchgate.net/publication/304952989_ Rendering_of_foreign_language_inclusions_in_the_Russian_translations_of_the_novels_by_Graham_Greene (Дата обращения - 29.11.2020).

18. Tartt D. The Goldfinch [Text] / D. Tartt. - New York: Little, Brown and Company, 2013. - 784 p.

(с Гацура Наталья Игоревна (n.gatsura@7gmail.com), Тирбах Анастасия Олеговна (anastasiya_tirbakh@mail.ru).

Журнал «Современная наука: актуальные проблемы теории и практики»

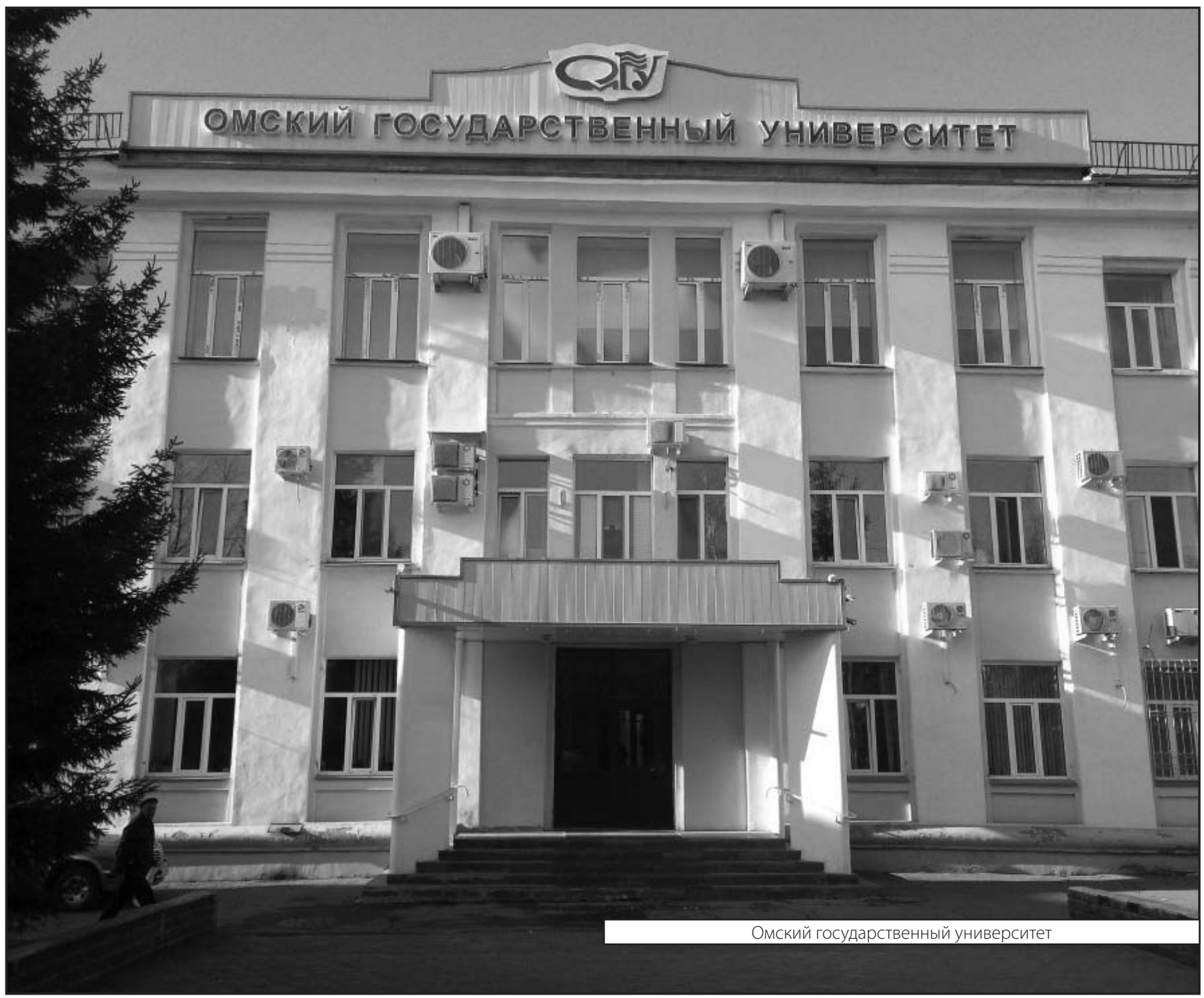

